Case for Teaching

\title{
HCFMUSP: Resilience in Response to the COVID-19 Pandemic
}

\section{HCFMUSP: Resiliência como Resposta à Pandemia de COVID-19}

Discipline: Strategy, Operations

\author{
Marcelo Caldeira Pedroso ${ }^{\circ}$ \\ João Teixeira Pires' 10 \\ Ana Maria Malik ${ }^{2}$ \\ Antonio José Rodrigues Pereira ${ }^{2}$
}

\section{INTRODUCTION}

On a cloudy day, March 11, 2020, infectious disease physician and coordinator of Coronavirus Contingency Center in São Paulo, Dr. David Uip, looked at his watch in the meeting room of Incor - Heart Institute, Hospital das Clínicas, Faculty of Medicine, University of São Paulo (HCFMUSP). It was just five minutes before noon, and all the doctors summoned to a scientific meeting on the new coronavirus were present. Quickly recalling the story of this new virus globally and in Brazil and very concerned with the prospect of its advancing disease in the state of São Paulo, he was unable to pay attention to the initial conversations of those present and asked for permission to start the meeting.

Joining Dr. David Uip were, among others, Dr. Fábio Jatene (vice president, Incor Board of Directors),

\footnotetext{
1. Universidade de São Paulo, Faculdade de Economia Administração e Contabilidade, São Paulo, SP, Brazil.

2. Fundação Getulio Vargas, Escola de Administração de Empresas de São Paulo, São Paulo, SP, Brazil.
}

Cite as: Pedroso, M. C., Pires, J. T., Malik, A. M., \& Pereira, A. J. R. (2021). HCFMUSP: Resilience in response to the COVID-19 pandemic. Revista de Administração Contemporânea, 25(spe), e200245. https://doi.org/10.1590/1982-7849rac2021200245.en
Dr. Esper Kallas (full professor, Department of Infectious and Parasitic Diseases, USP Medical School), and Dr. Marcelo Amato (doctor, intensive care specialist) to talk about the spread of the disease. The coordinator began by reporting that the prospect of an explosion of new coronavirus cases in São Paulo was evident, as community transmission had already been recognized (when the contamination source is not identified). Some essential pieces of information were discussed as the meeting followed agenda. Comparing tests performed on patients in China and Brazil revealed a similarity in the aspect of their lungs' images. Tomography and simple X-ray tests were required to identify the infections for the diagnosis of the disease.
JEL Code: A20, 118, L1 Editor-in-chief: Wesley Mendes-da-Silva (Fundação Getulio Vargas, EAESP, Brazil) (t) Associate Editor: Paula C. P. de S. Chimenti (Universidade Federal do Rio de Janeiro, COPPEAD, Brazil) (0) Guest Editor: Leonardo Marques (Universidade Federal do Rio de Janeiro, COPPEAD, Brazill) Reviewers: Cláudia Araujo (Universidade Federal do Rio de Janeiro, COPPEAD, Brazil) (c) Luiz Carlos Di Serio (Fundação Getulio Vargas, EAESP, Brazil) (])

Peer Review Report: The Peer Review Report is available at this external URL.

Received: July 25,2020 Last version received: December 16, 2020 Accepted: December 27, 2020

\begin{tabular}{|c|c|c|c|c|c|c|c|c|c|}
\hline & 1 & 2 & 3 & 4 & 5 & 6 & 7 & 8 & 9 \\
\hline $1^{\text {st }}$ round & & $\stackrel{9}{2}$ & & & & & & & \\
\hline $2^{\text {nd }}$ round & & & & & & & & & \\
\hline $3^{\text {rd }}$ round & & & & & & & & & \\
\hline
\end{tabular}


After the meeting, audio by Dr. Fábio Jatene circulated, mainly through WhatsApp, highlighting the needs of ICU beds for the treatment of the new coronavirus ${ }^{1}$ : "Forty-five thousand cases are expected in the Great Sáo Paulo in the next four months, which will require ICUs in 10 to 11 thousand cases. Moreover, we do not have 10 thousand ICU beds," said Jatene.

This information stirred a feeling of panic in the general population. At a press conference held a few days later, Dr. David Uip confirmed the estimates made by Jatene but tried to assuage by saying: "... this is the worstcase scenario."

The São Paulo health system would collapse if the worst scenario were to materialize, a situation in which the demand for medical care overly exceeds capacity. Given the severity and progress of the disease, people would die at home without access to treatment.

The international epidemiological situation showed a rapid spread of cases. According to the European Center for Disease Prevention and Control (ECDC), 30\% of cases of infection with the new coronavirus (COVID-19) remained asymptomatic; $56 \%$ had moderate symptoms and could be treated at home; $10 \%$ needed treatment in inpatient units (infirmary); and only $4 \%$ progressed to the need for ICU care, requiring mechanical ventilation.

In the specific case of infection with the new coronavirus, the parameters seemed different from what is seen in general: the mean stay of the patient with COVID-19 in the ICU was 15 days so that each bed could be used by only two patients/month. A troubling situation was that the occupation routinely observed in the HCFMUSP ICU beds was already $85 \%$ of the installed capacity for all diseases. At this rate, the setting of a potential collapse in the health system was realistic.

The doctors raised other issues. There was still no vaccine for prevention and a limited capacity to process blood tests (particularly the RT-PCR test - real-time polymerase chain reaction, considered the gold standard for COVID-19 diagnosis) to diagnose the disease. CT scans are expensive tests, and their availability is limited. Regarding possible treatments, there was no evidence of the effectiveness of specific drugs against the new coronavirus, requiring time and investment in research and development.

The doctors present looked at each other. A brief and deafening silence crept in Incor's meeting room: how could the HCFMUSP react to this imminent health crisis? Three simultaneous actions were outlined: (1) Installation of the HCFMUSP Crisis Management Committee COVID-19, to address adaptations of operations in the face of the emergency; (2) Increased capacity of intensive care units (ICUs) by restructuring the operations of the Central
Institute of HCFMUSP (the largest and oldest institute of the complex). This would become a center dedicated to COVID-19 treatment, which would include relocating patients and postponing surgeries and elective procedures; (3) Development of new diagnostic and therapeutic protocols, with the need to incorporate knowledge from different medical specialties and synchronize actions with professors and researchers from the USP School of Medicine and keep them updated with new developments.

Are these three lines of action sufficient to prevent the collapse in the care of patients with COVID-19 at HCFMUSP? How would its operations respond to the future unprecedented demand?

\section{OVERVIEW OF THE EMERGENCE OF THE NEW CORONAVIRUS GLOBALLY AND IN BRAZIL}

In December 2019, the WHO (World Health Organization) issued an alert over several cases of pneumonia in the city of Wuhan, Hubei province, China, originating from the infection caused by a new type of coronavirus. In the first week of January 2020, Chinese authorities confirmed that they had found this new coronavirus, later called SARS-CoV-2 (severe acute respiratory syndrome CoronaVirus-2), which caused the disease that came to be called COVID-19 (coronavirus disease-19).

Its spread was then identified in other countries, mostly European, mainly those that received people from China. The fastest and least controlled dissemination occurred through air transport, but some ships were prevented from docking in several countries until they showed evidence that their passengers and crew had no disease symptoms. The first case recorded outside China was in Thailand on January 13, 2020. After that, episodes of the disease were confirmed in Japan (January 16); South Korea (January 20); Taiwan and the U.S. (January 21); Hong Kong and Macau (January 22); Singapore (January 23); France, Nepal, and Vietnam (January 24); Malaysia and Australia (January 25); Canada (January 26); Cambodia (January 27); Germany (January 28); Finland, United Arab Emirates, and Sri Lanka (January 29); Italy, India, and the Philippines (January 30); and the United Kingdom (January 31).

In Brazil, after Carnival, when many Brazilians spent their holidays abroad (in Europe and the East), and foreigners enjoyed the festivities in the country, besides the intense internal air and road traffic, the first COVID-19 case was confirmed in São Paulo on Ash Wednesday (February 26). It was a 61-year-old man with a history of traveling 
to Italy who, at that time, was experiencing a significant increase in cases of the disease.

With a posteriori criticism on the opportunity to have the carnival festivities suspended, the slow initial growth of cases in Brazil began to be observed. Information about the rapid spread of the disease in Europe, China, and Japan raised press alerts. Preparations began at the Ministry of Health and the São Paulo State Health Secretariat, such as surveying the number of available beds for mild cases and those requiring ICUs.

\section{THE CONTEXT OF THE HEALTH SECTOR AND ITS APPLICATION TO THE PANDEMIC}

The Brazilian Unified Health System (SUS) consists of two subsystems: the public and the private. The HCFMUSP serves mainly the public sector, with less care to private patients. The health system is complex and can be better understood from its value chain. Annex A presents this chain consisting of six vertical and three horizontal links.

Knowledge is the leading health value chain input, as this is a knowledge-intensive sector. This is incorporated into products (medicines) and technologies (robot-assisted surgery). These products and technologies are used in health services, including health promotion activities, disease prevention, diagnosis, treatment, rehabilitation, and management of chronic diseases. The following links represent financial intermediation and health financing activities, reaching the final link, patients, healthy individuals, and firms. The other three links permeate those mentioned above and consist of regulation, distribution of health products and services, and support and supplementary services.

The harmonious functioning of all links was essential for the care of COVID-19 patients, starting at the end, healthy patients and individuals, with adherence to treatment and prevention (in this case, through compliance with social distancing and basic hygiene rules).

In the financing link, all government funds released should be approved by the Ministry of Economy on an emergency basis. There was also intense mobilization by the National Congress to release additional resources to combat the pandemic.

In the regulation link, the need for integration between the three administrative spheres is highlighted: federal, state, and municipal, reflected in the guidelines of the Ministry of Health and the State and Municipal Health Secretariats to act in the pandemic. Also, we can mention Anvisa's action in releasing respirators, medicines, and vaccines.
Financial intermediation includes rules for accessing the health system, such as using the Cross system (Regulation Center for the Provision of Health Services), of the São Paulo State Health Secretariat, for the regulation of ICU beds for patients.

Concerning health services, their operation implied the need to have qualified and specialized professionals to develop and implement new protocols for the care of COVID-19 patients. In this link, it was of utmost importance to assess the system's service infrastructure. In this sense, an important indicator is the number of public and private beds per thousand inhabitants. According to OECD data, Brazil has an indicator of 1.98 beds/1,000 inhabitants. Annex B shows this indicator, comparing it with that of different countries.

Concerning the supply of products and equipment, noteworthy is the global mobilization for the purchase of protective masks and respirators, implying a great challenge, given the dependence on the Chinese producer market. China still experienced the effects of the disease and could not supply the global demand. Some challenges persisted, specifically in Brazil, and were inherent to distributing products and services throughout the national territory from this supply framework. This distribution should meet criteria that establish priority locations for the distribution of these supplies, requiring coordination between different government levels to safely send materials/equipment to the necessary locations. In the Support and Supplementary Services link, worth mentioning is the clinical engineering activity in the ICU equipment maintenance. Completing the links, the importance of knowledge development arises. The development of vaccines and the discovery of new treatments stand out and include drugs that could directly combat the virus or its penetration in human cells and block its side effects.

\section{THE HCFMUSP COMPLEX: HOSPITAL DAS CLÍNICAS, FACULTY OF MEDICINE, UNIVERSITY OF SÃO PAULO}

The HCFMUSP was founded on April 19, 1944, as a teaching hospital linked to the USP School of Medicine (which, in 2020, offered training in Medicine, Physiotherapy, Speech Therapy, and Occupational Therapy). In 2020, the HCFMUSP (also called HC) was considered the most extensive public hospital complex in Latin America, focusing on highly complex services. It was linked to the São Paulo State Health Secretariat for administrative coordination purposes and consisted of eight specialized institutes and two auxiliary hospitals, with a total area of 600 thousand $\mathrm{m} 2$ and a capacity of 2,400 beds. That year, the eight institutes and their respective founding years were: 
1. Central Institute (ICHC - 1944);

2. Institute of Psychiatry $(\mathrm{IPq}-1952)$;

3. Institute of Orthopedics and Traumatology (IOT 1953);

4. Institute of Physical Medicine and Rehabilitation (Imrea - 1975);

5. Children Institute (ICr-1976);

6. The Heart Institute (Incor - 1977);

7. Institute of Radiology (InRad - 1994);

8. Cancer Institute of the State of São Paulo (Icesp 2008).

In 2020, HCFMUSP had the following vision: "to be an institution of excellence, recognized nationally and internationally in teaching, research, and care." Ethics, humanism, social responsibility, pluralism, pioneering spirit, and institutional commitment were the values that guided the conduct of its professionals and its relationship with its various stakeholders to achieve this vision. According to Dr. Aluisio Segurado, professor of Infectious Diseases at USP and current director of the Board of Directors of the Central Institute, the establishment of the complex was anchored in the spirit of teacher-specialist unity.

Concerning governance, the top management of the HCFMUSP consisted of the Deliberative Council, Advisory Council, Clinical Directorate, and the Superintendence. The Deliberative Council's plenary was composed of a president (director of the Faculty of Medicine of USP FMUSP), a vice president (vice director of FMUSP), and seven full FMUSP professors. The executive functions were incumbent upon the Superintendence and the Clinical Board. The superintendent was appointed by the governor of São Paulo, while the clinical director was elected from among the full and alternate members of the HCFMUSP Deliberative Council.

The Superintendence was responsible for executive functions. Under its management were: (a) Executive directors of the institutes: one executive director per institute and for each of the auxiliary hospitals; (b) Directors of Technical and Administrative Centers: covered the areas of infrastructure and logistics, finance, law, information technology, planning and management, hospital engineering and architecture, personnel management, institutional communication, supplementary health, and health technology assessment.

The adopted organizational structure can be considered as a matrix. The institutes carried out the core activities of a welfare nature; the Technical and Administrative Centers were responsible for the institutes' activities and support.
The Clinical Board's mission was to promote the development of health actions and services in support of professional training, aiming at comprehensive patient care in a teaching hospital. In the care functions, the clinical director spearheaded Technical and Scientific Centers, working in different areas: Speech Therapy, Occupational Therapy, Physiotherapy, Diagnostic Imaging, Anesthesiology, Infectology, Telemedicine, Intensive Care, Pharmacy, Nursing, Humanization, and Palliative care.

Within the complex was the HCFMUSP Clinical Research Office, acting as a facilitator, with multidisciplinary and multiprofessional activities, which fostered the promotion, development, and integration of clinical research. It was a fundamental organization for the management of innovation and knowledge, with a leading role in identifying new treatments for diseases and ways of promoting and recovering health. Annex $\mathrm{C}$ presents the HCFMUSP organization chart in 2020.

\section{HCFMUSP'S ACTION AGAINST THE COVID-19 PANDEMIC}

\section{The Crisis Committee: a governance response to fight the pandemic}

The Crisis Committee within the HCFMUSP Governance System was activated for the first time in 2015 when emergency care was needed for yellow fever patients. In 2018, when truck drivers went on a nationwide general strike, this committee was also called to anticipate potential damages of the lack of supplies, materials, and equipment in its facilities. The HCFMUSP Crisis Committee adopts a protocol based on the "Hospital Incident Command System (HICS)." It is a methodology developed in California (U.S.) geared to hospitals to establish procedures and regulations for acting in disasters concerning the conduct of health emergencies recommended for situations of natural and public health disasters.

In late January 2020, the Crisis Committee was installed again to plan and implement practices to combat the impending pandemic. It was led by the HC Clinical Director Dr. Eloísa Bonfá and coordinated by Dr. Beatriz Perondi. The committee met daily to discuss pandemicrelated events and the preparation of the complex to provide care to patients. This committee had to design a proposal for action, which should meet the following guidelines:

1. Improve care for COVID-19 patients through specialized protocols;

2. Ensure continuity of the institutional mission of the HCFMUSP, within the hierarchy of SUS services 
in the state of São Paulo, providing highly complex services;

3. Minimize the risk of cross-infection (patients acquiring COVID-19 in the hospital environment) and transmission of the virus to healthcare professionals.

Initially, implementing service areas for the treatment of COVID-19 in each institute in the complex was envisaged. However, with the already evident signs of high infection levels and the significant proportion of HC professionals within risk groups, the possibility of greater care centralization was considered. Everything led to the proposal to promote the Central Institute's total isolation to exclusively serve patients with this diagnosis, despite the significant implementation challenges. Among them, the need to transfer 450 severely ill patients treated at the Central Institute and redirect emergency care, with all its diversity of equipment and professionals involved.

Once the proposal has been organized, it should be submitted to the approval of the Institute Council (Condir) and the Deliberative Council of the HC Complex (Condel), whose regular meeting was scheduled to take place on March 23.

\section{Decision-making: visit of São Paulo State governor}

Everything was happening so that the Deliberative Council considered the proposal for the Central Institute's isolation to assist COVID-19 patients at the end of March. However, a visit by the then governor of São Paulo João Doria to the premises of the Central Institute in the late afternoon of Sunday (March 22) accelerated decision-making ${ }^{2}$. Upon becoming aware of the Central Institute's idea of isolation, placing 200 beds available to care for COVID-19 patients in the ICU (complementing a 38-bed ICU agreement, signed in March 2020 for the same purpose) and 700 beds for hospitalization in infirmaries, the governor immediately approved it. He activated his social networks and other media to disseminate the information: "... the 200 new ICU beds will be fully operational next Friday, March 27. Then we can have an additional 50 to 100 new ICU beds here at Hospital das Clínicas," said Governor João Doria.

The State Health Secretariat supported this decision: "It is essential to count on the excellence of the Hospital das Clínicas of FMUSP to face this crisis. The State Health Secretariat is fully supporting the equipment and hiring personnel so that these new units provide the best for our population," reinforced São Paulo State Health Secretary José Henrique Germann Ferreira.
The decision triggered a reaction of discomfort, given that the proposal had not yet been submitted to the HCFMUSP Deliberative Council and would require the approval of its members to take effect. In particular, the support of the other 35 full professors responsible for the Central Institute's activities and the full professors allocated in the other institutes of the complex was required. This alignment would be essential to enable an action to secure the management of the expected crisis in an orderly and effective manner. It was time to give a categorical answer to the state government and society to avoid the collapse in patient care during the pandemic.

\section{The mobilization to implement the decision}

Faced with the decision to concentrate the care of COVID-19 patients at the Central Institute, the committee needed to transfer 450 patients previously hospitalized there and prepare 200 ICU beds and 700 infirmary beds.

To this end, it was necessary to consider all the challenges and obstacles concerning the availability of personal protective equipment (PPE) for employees, equipment such as mechanical ventilators, respirators, and infusion pumps, information technology services for patient control, and, especially, preparing human resources to act at the frontline of the fight against the pandemic. For HCFMUSP, within the COVID Agreement signed with the State Health Secretariat (SES), this represented a daily cost of R\$2,231 per ICU bed and R \$ 906 per infirmary bed.

The patients treated at the Central Institute should come from referrals defined by the Unified Health System in the state of São Paulo, through the Cross system (Regulation Center for the Provision of Health Services). This system would be responsible for directing the most severe COVID-19 patients, whose care could not be done in other resources designed for less critical care, such as field hospitals.

\section{Demand management: the role of Cross and the On-call Control service}

As previously mentioned, within the SUS, the Regulation Center for the Provision of Health Services (Cross) was responsible for the regulation of beds for the treatment of COVID-19 in the state of São Paulo, according to vacancies agreed by the HCFMUSP (and other institutions) with the São Paulo Health Secretariat. As a result, Cross had a regulatory effect on the demand perceived by HCFMUSP.

Thus, the HCFMUSP was hired to provide a service capacity (that is, ensuring bed availability) to treat COVID-19 patients in the state of São Paulo. Cross allocated patients 
by criteria of urgency, severity, and regionalization. Thus, in this last criterion, the HCFMUSP would preferentially receive patients from the South and West regions of São Paulo's municipality and state macro-regions of Rota dos Bandeirantes, Mananciais, and Vale do Ribeira.

Cross requests for referrals to patients were received by the HCFMUSP on duty, which is an Internal Regulation Center (NIR). This center consisted of a team with $24 / 7$ availability (24 hours a day, every day of the week). This team is specific to this function, and it evaluated the relevance of referrals for patient acceptance. The following guidelines were adopted for the regulation of suspected and confirmed COVID-19 cases:

- Cross created a specific form (called the Flu-like Syndrome Form) to structure the most relevant data related to this patient profile and facilitate the assessment.

- It was agreed with Cross that HCFMUSP would be a reference for COVID-19 cases of greater severity or requiring specialists (e.g., obstetrics, vascular surgery, neurosurgery), even if they were in regions that were usually under the responsibility of the HCFMUSP. Thus, Cross forwarded requests from all regions of the city of São Paulo and the Greater São Paulo (at a given moment, even from the state inland region), and the On-call Control service accepted the transfer of the most severe/complex cases that were in locations with deficient support structure, considering the HCFMUSP service capacity at the time.

- The HCFMUSP On-Call Control service doubled the medical regulation team, including infectologists, so one of the doctors was dedicated exclusively to assessing Cross requests and HCFMUSP's service capacity to streamline patient transfer times.

- The On-Call Control service also regulated ambulances from a donor company based at the HCFMUSP. These ambulances searched for critically ill patients whose transfers had been authorized, significantly reducing transfer time.

\section{The first expansion of service capacity}

The HC allocated all beds at the Central Institute (ICHC) to treat patients affected by COVID-19 during the pandemic. To this end, it transferred patients from other specialties to the other institutes in the hospital complex. As a result, the Central Institute became the largest hospital operation of intensive care units (ICU) in Brazil, with two hundred beds. This action was considered by HCFMUSP as the "most audacious operation in its 76 years of existence," according to a manifest released on June 8,2020 , by the professors of the Faculty of Medicine of USP.

The first capacity expansion from 84 to 200 ICU beds was formalized and approved through an agreement with the State Health Secretariat. This agreement totaling $\mathrm{R} \$ 159$ million would last six months and had a Work Plan including needs for human resources, materials, drugs, and equipment. Approximately R $\$ 7.2$ million was allocated to equip the ICUs.

Human resources' challenge was critical, hiring and training professionals to face the pandemic and mobilizing professors from the Faculty of Medicine, whose support was essential for the undertaking's success. Around 1.8 thousand of the 6 thousand professionals working at the Central Institute had to follow the recommendation made by USP, of which the Faculty of Medicine is part, to work in a home office regime since they belong to COVID-19 risk groups. Thus, in a short period, it was necessary to hire 1.8 thousand employees to replace them, on the front line and in administrative functions, all with a Consolidated Labor Laws (CLT) contract for a specific time, until September 2020. In this sense, significant support was received from private hospitals of excellence, such as AACD, Albert Einstein, BP (Portuguese Beneficence of São Paulo), HCor (Heart Hospital), Rede D'Or, and the Syrian-Lebanese Hospital, which supported the training of health professionals and the availability of doctors, nurses, and physiotherapists.

The teams were reinforced with assistants from different medical specialties from the staff of the Central Institute and resident doctors. All relevant procedures for treating the disease, such as intubation, mechanical ventilation, pronation (positioning the patient face down to promote better respiratory flow), and protection of professionals (such as PPE dressing and undressing procedures), had specialists on each team. Training videos were also prepared for each of the main procedures, establishing 'rapid response teams' for emergency processes.

The mobilization of the group of professors at the Faculty of Medicine was a challenge: $90 \%$ of them had to leave the frontline because they belonged to risk groups. They started to work remotely, leading to a reduction in their sense of urgency compared to those on the front line, facing daily challenges. In addition, concerned with the risks faced by their respective teams, teachers were not willing to allow performing some procedures necessary to combat the disease. This required persuasion and constant communication to ensure alignment. In this context, noteworthy is the initiative of the president of the Deliberative Council of the complex Dr. Tarcísio Barros to create a WhatsApp group, which became a communication channel between teachers and provided the necessary agility for this group to work with their teams. 
Direct support from private companies and hospitals was significant and comprehensive in this first stage. BTG Banco Pactual contributed directly to new intensive care doctors' remuneration, and around 2,000 on-callers were recruited. Attracting these professionals required increasing the amount paid per on-call shift, which was $\mathrm{R} \$ 1,120$ before the pandemic. In the pandemic, this specialist was not attracted for less than $\mathrm{R} \$ 1,900 /$ on-call shift, an amount incompatible with the HC budget. BTG Pactual covered this difference at a critical time for the team to assemble. Rede D'Or and Banco Bradesco donated R \$ 1 million each and supported the establishment of teams of professionals. Rede D'Or was also responsible for the work of 150 support and administrative professionals.

There was an intense mobilization of HCFMUSP professionals around donation campaigns, financial resources, and services. The companies Grupo Península, B3 Investimentos, Natura Cosméticos, Banco Pactual, and São Paulo families engaged in this health investments chain. A donation committee was set up, audited by $\mathrm{PwC}$ (PricewaterhouseCoopers).

This first stage witnessed a discontinuous flow of materials, medicines, and PPE. There was a massive transfer of mechanical ventilators from the other institutes to the Central Institute, which did not meet the demand. Anesthesia equipment for mechanical ventilation was used as about $80 \%$ of the ICU patients were intubated. In addition, three out of ten patients admitted to the ICU required hemodialysis, which required articulation with specialists for this type of care. Finally, the logistics required for the distribution of these items was challenging, considering the total number of employees in the complex (20 thousand professionals) and their anxieties regarding orientation changes, since initially only care professionals should wear masks; then all workers would use them; finally, they were recommended for everyone.

It is also worth highlighting the need for changes in the layout in the facilities of the Central Institute, where former teachers' rooms were transformed into administrative units (bedrooms, changing rooms, pantries, and rest and training areas for nursing and technicians), which required convincing their former users.

\section{Second service capacity expansion}

At the end of April 2020, the Central Institute reached $98 \%$ occupancy of its ICU beds. Thus, it was necessary to prepare an urgent expansion. On April 23, 196 patients occupied the 200 intensive care beds reserved for the disease. The need to expand the ICU's service capacity by an additional 100 beds was calculated, totaling 300 .
According to the executive director of the Central Institute, Dr. Lucila Pedroso da Cruz, this would be done by transforming infirmary beds into ICU beds, triggering several adaptations, including gas network infrastructure, support for stables, and electrical network for the equipment. In standard infirmary beds, a COVID-19 patient whose oxygen $\left(\mathrm{O}_{2}\right)$ saturation level should be checked required strict attire from any professional who would perform this procedure. A partnership was celebrated with telecom company Vivo to facilitate the process, which installed a wifi network inside the $\mathrm{HC}$ to allow continuous monitoring of patients, whose data were sent directly to nursing, without the need for individual measurement.

The additional 100 beds were divided into 20 ICUs located in separate spaces. Each had its team of intensive care physicians, nurses, and physiotherapists. Some of these ICUs were operated by private organizations. These private organizations were responsible for managing the shifts, the medical team, and the use of equipment, beds, monitors, and infusion pumps.

Resizing the human resources framework for the ICHC required adapting to the number and type of beds in this new stage: 500 in the infirmary and 300 in the ICU. Hence the consequences, such as the number of qualified professionals, needs for PPE, and equipment. Regarding PPE, there were differences between the kits for the infirmary and the ICU. A specific ICU was created for the care of pregnant patients in severe conditions. Patients with psychiatric diagnoses also required specialized care, implying adaptations to existing systems.

Coinciding with the second stage of the expansion, the supply of medicines suffered its worst period in April, requiring close monitoring of the supply area to avoid service collapse. There were also difficulties with the supply of disposable aprons: its Chinese supplier diluted the supply due to competition in the market for its consumption.

\section{Possible COVID-19 treatments}

Several therapeutic hypotheses were being researched: new drugs, drugs with proven action in other diseases, and new forms of treatment to fight the virus or mitigate its effects. There was still no evidence of drugs that could eliminate the new coronavirus. The initial challenge was to keep the patient alive until his immune system overcame the disease. Studies that were being carried out on criticallyill patients, both those who died and those who survived, signaled that the infection was systemic, with reactions that could trigger thrombosis, strokes, ischemic injuries, heart attacks, impairments of the cardiac muscle and even the nervous system. In other words, the initial treatment 
protocols focused on measures to support the maintenance of the patient's life and not the direct fight against COVID-19.

A teaching hospital, the HCFMUSP had a firm institutional position aimed at supporting scientific evidence. The various drug alternatives should be subjected to research, including cases of patients in ICUs. The hospital structure and the number of patients would allow comparing the use of various drugs in patients from groups with similar clinical conditions. The protocol would follow strict inclusion and exclusion criteria and continuous monitoring to be suspended if necessary.

At that moment, the world was crying out for a possible solution to the pandemic: the vaccine against COVID-19. The process of developing a new vaccine is relatively long, and the development of a vaccine against COVID-19 was still embryonic. It was not possible to predict when this vaccine would be available.

\section{NEXT STEPS}

The month of May 2020 arrived. The measures to implement exclusive care for COVID-19 patients at the Central Institute had already been taken. Until then, the HCFMUSP had shown its management and mobilization capacity to overcome the pandemic's immediate challenges. In the words of one of the professors: "... the efforts made have revived the spirit of Hospital das Clínicas, the feeling of belonging of everyone to the larger entity with a mission to fulfill.”
At the time, the 300 ICU beds had a high mean occupancy rate (93\%); the mean length of stay was 12 days, less than expected (15 days); and the lethality rate of the disease was 25\% (Annex D). Then, new questions arose for the Crisis Management Committee - COVID-19 of the HCFMUSP:

How should the HCFMUSP proceed in the face of the advance of the pandemic? Further increase the service capacity in ICUs? In that case, how? Maintain the installed capacity, given that the regulation (carried out by the Cross system and by the On-call Control service) would not allow the collapse in its attendance (without this ensuring to avoid the collapse in the attendance of the health system of the state of São Paulo)? Or start the process of demobilizing the actions carried out aiming at their operational rebalancing (and, therefore, to meet the repressed demand of patients with other diseases)?

Another challenge was launched!

\section{NOTES}

1. G1. (2020). Audio de médico do Incor sobre avanço do coronavírus em SP é verdadeiro, mas é 'a interpretação de um cirurgião', diz David Uip. Retrieved from https://gl.globo.com/sp/ sao-paulo/noticia/2020/03/12/audio-de-medico-do-incorsobre-avanco-do-coronavirus-em-sp-e-verdadeiro-mas-e-ainterpretacao-de-um-cirurgiao-diz-david-uip.ghtml.

2. Isto É. (2020). Doria entrega novos leitos de UTI no Hospital das Clínicas em São Paulo. Isto É. Retrieved from https:// istoe.com.br/doria-entrega-novos-leitos-de-uti-no-hospitaldas-clinicas-em-sao-paulo/ 


\section{ANNEX A.}

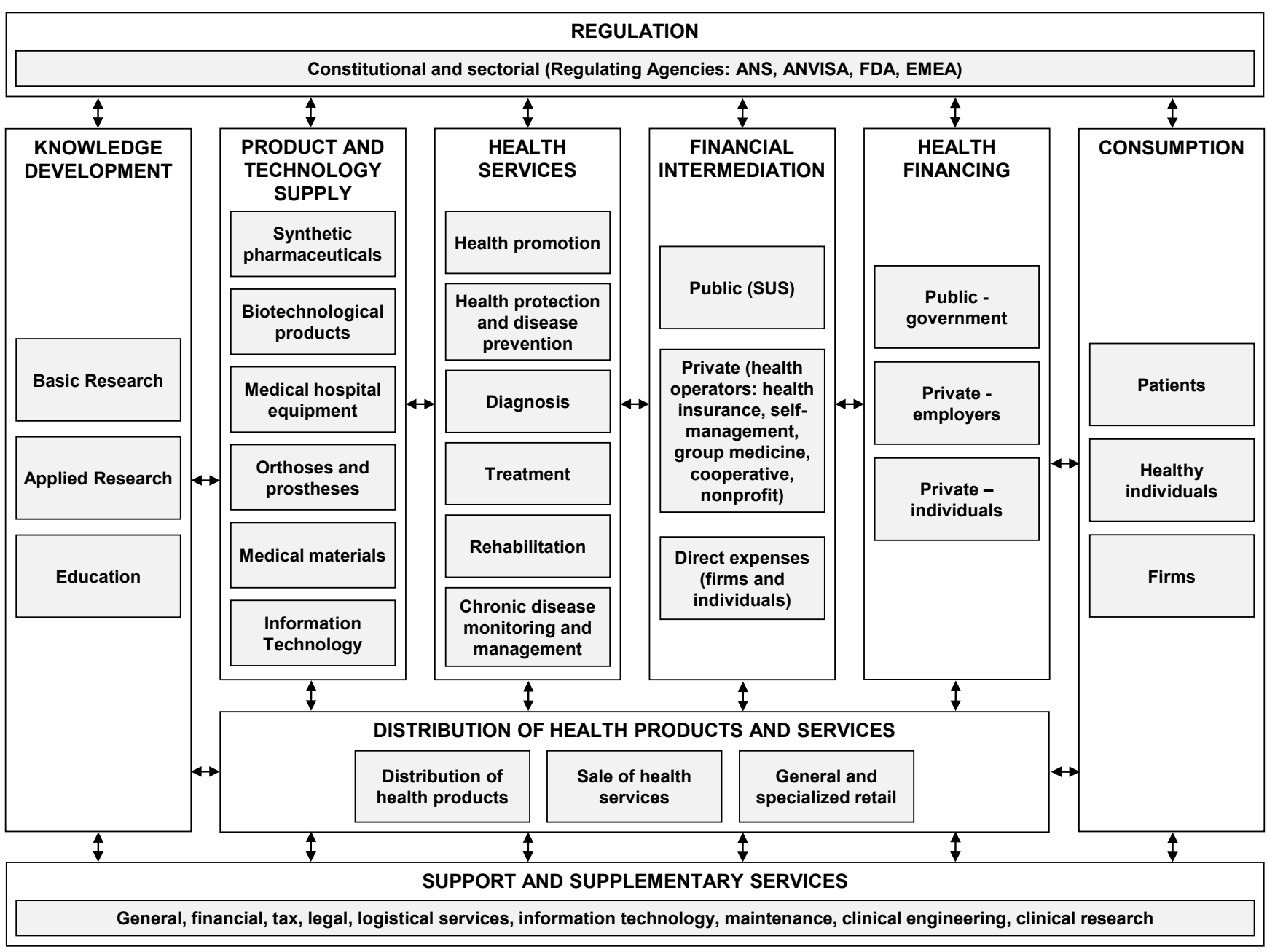

Figure A1. Health value chain.

Source: Pedroso, M. C., \& Malik, A. M. (2012). Cadeia de valor da saúde: Um modelo para o sistema de saúde brasileiro. Ciência \& Saúde Coletiva, 17(10), 2757-2772. https://doi.org/10.1590/s1413-81232012001000024 


\section{ANNEX B.}

\section{Beds $/ 1,000$ inhabitants}

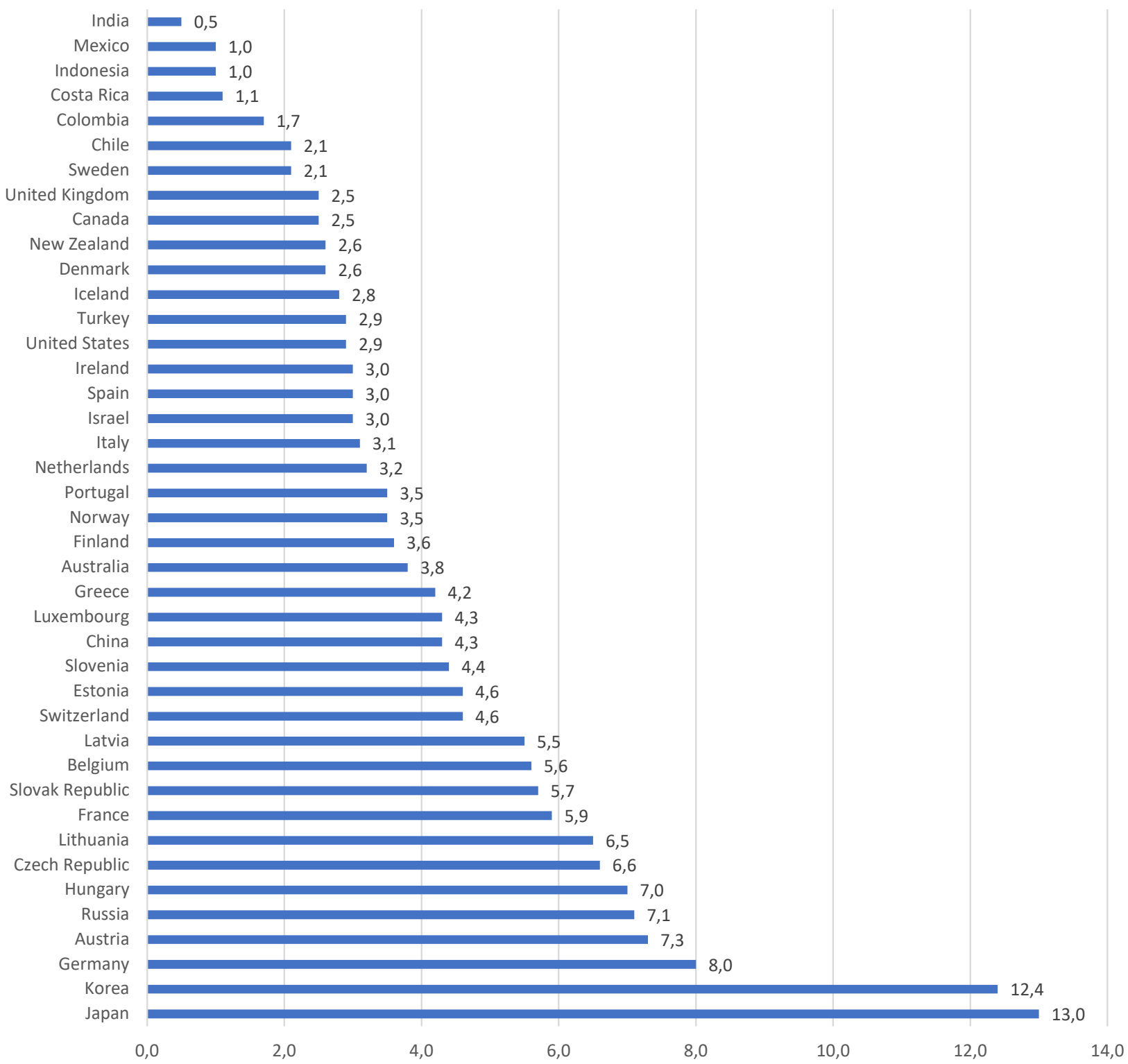

Figure B1. Beds per thousand inhabitants in different countries.

Source: Organisation for Economic Cooperation and Development. (2020). OECD Health Statistics (database). https://doi.org/10.1787/data-00541-en 


\section{ANNEX C.}

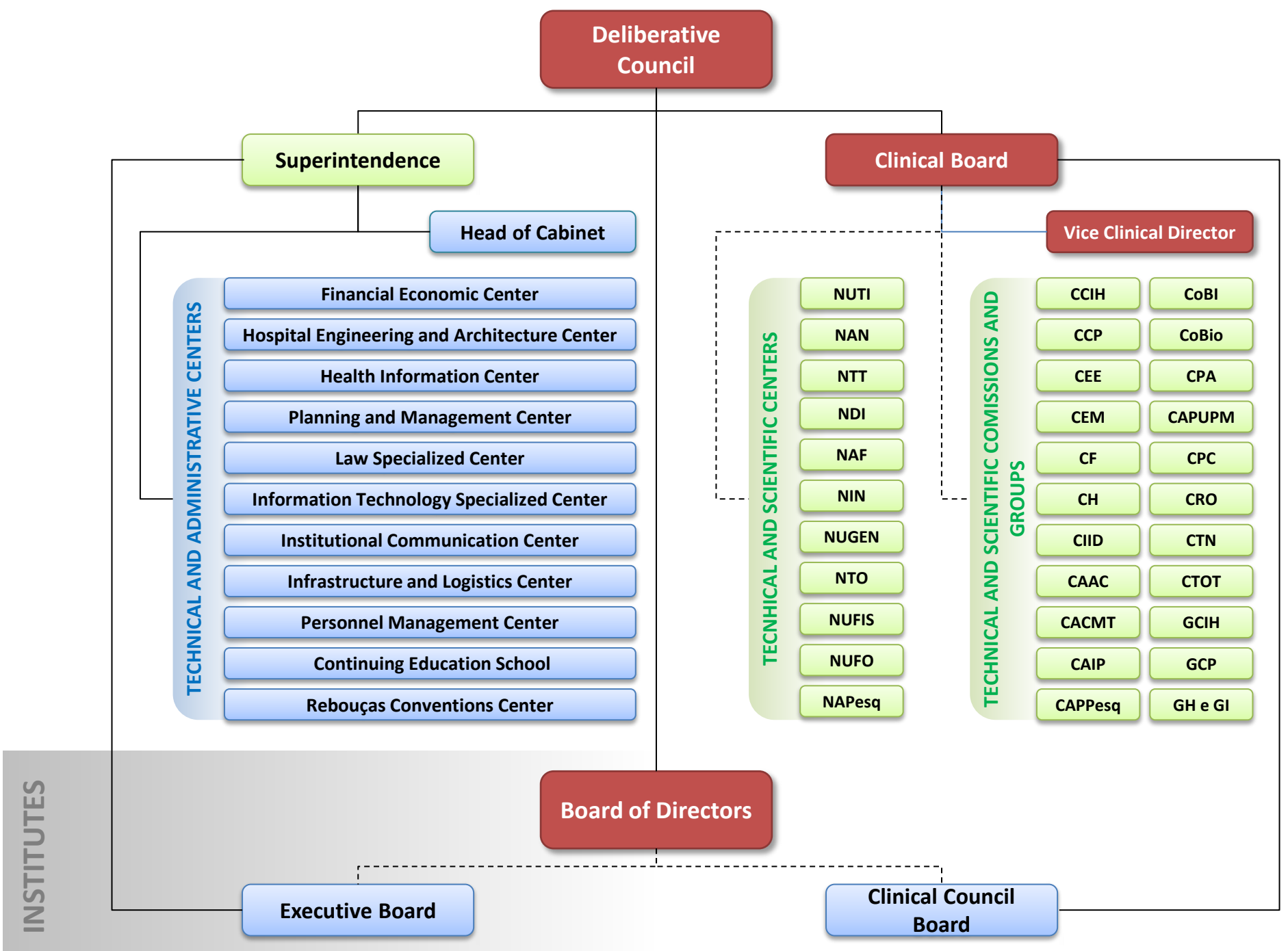

Figure C1. Organizational chart of HCFMUSP.

Source: HCFMUSP. 


\section{ANNEX D.}

ICHC: Bed availability

\begin{tabular}{|c|c|c|c|c|c|c|c|c|c|c|c|}
\hline \multicolumn{4}{|c|}{ March } & \multicolumn{4}{|c|}{ April } & \multicolumn{4}{|c|}{ May } \\
\hline ICU & INFIRMARY & PS & TOTAL & ICU & INFIRMARY & PS & TOTAL & ICU & INFIRMARY & PS & TOTAL \\
\hline 124 & 752 & 34 & 910 & 232 & 723 & 34 & 989 & 300 & 695 & & 1,029 \\
\hline
\end{tabular}

Operational occupancy rate

\begin{tabular}{|c|c|c|c|c|c|c|c|c|}
\hline \multicolumn{3}{|c|}{ March } & \multicolumn{3}{|c|}{ April } & \multicolumn{3}{|c|}{ May } \\
\hline ICU & INFIRMARY & PS & ICU & INFIRMARY & PS & ICU & INFIRMARY & PS \\
\hline $85.07 \%$ & $71.21 \%$ & $82.36 \%$ & $91.43 \%$ & $72.88 \%$ & $45.07 \%$ & $93.29 \%$ & $70.65 \%$ & $46.93 \%$ \\
\hline
\end{tabular}

Mean stay

\begin{tabular}{|c|c|c|c|c|c|c|c|c|}
\hline \multicolumn{3}{|c|}{ March } & \multicolumn{3}{|c|}{ April } & \multicolumn{3}{|c|}{ May } \\
\hline ICU & INFIRMARY & PS & $\mathrm{ICU}$ & INFIRMARY & PS & ICU & INFIRMARY & PS \\
\hline 5.49 & 5.46 & 3.79 & 11.94 & 8.25 & 4.26 & 11.67 & 8.98 & 3.93 \\
\hline \multirow[t]{2}{*}{ Lethality rate } & & & \multicolumn{6}{|c|}{ April } \\
\hline & Rate & & \multicolumn{6}{|c|}{$24.93 \%$} \\
\hline \multirow[t]{2}{*}{$25.39 \%$} & Deaths & & \multicolumn{6}{|c|}{252} \\
\hline & Hospitalizations & & \multicolumn{6}{|c|}{1,011} \\
\hline
\end{tabular}

Figure D1. Hospital indicators of the Central Institute (March to June 2020).

Source: HCFMUSP, PIH — Hospital Intelligence Platform. 


\section{Teaching Notes}

\section{ABSTRACT}

The teaching case describes a set of emergency actions taken by HCFMUSP to manage the needs brought by the COVID-19 pandemic in Brazil. The case objective considers the issues related to the impact of the pandemic mostly in healthcare operations, emphasizing how to: (a) adapt health system governance in response to a crisis (crisis management); (b) manage the health system capacity, which traditionally is not so resilient; (c) deal with a new disease (knowledge management). Thus, it should allow gathering elements for the management of future crises.

Keywords: healthcare management; health systems; crisis management.

\section{PREPARATION}

This case could be geared to undergraduate and graduate stricto and lato sensu students, aiming to improve knowledge, skills, and attitudes for crisis management and organizational adaptability, not only in health.

Students must acquire knowledge about how the health value chain operates (essential due to the sector's complexity and particularities) and how to manage the capacity to provide care in health services. The case considers an exceptional situation (triggered by the pandemic) and the need to incorporate new knowledge (as it is a new disease), elements associated with governance and knowledge management. Thus, the suggested preliminary bibliography would be (Bayntun, Rockenschaub, \& Murray, 2012;

\section{RESUMO}

O caso de ensino descreve um conjunto de ações emergenciais empreendidas pela gestão do HCFMUSP para responder às necessidades provocadas pela pandemia do COVID-19 no Brasil. O objetivo deste caso considera temas relacionados ao impacto da pandemia na área de operaçóes em saúde, com ênfase em: (a) adaptação da governança como resposta a uma crise (gestão de crises); (b) readequaçáo da capacidade produtiva de uma operação tradicionalmente considerada pouco resiliente; (c) aprendizado de como tratar uma nova doença (gestão do conhecimento). Sendo assim, permitirá reunir elementos para a gestáo de crises futuras.

Palavras-chave: gestão em saúde; sistemas de saúde; gestão de crise.
Bennington, 2010; Bohmer, 2009; Paim, Travassos, Almeida, Bahia, \& Macinko, 2011; Pedroso \& Malik, 2012; Vecina Neto \& Malik, 2016; Zane \& Prestipino, 2004).

Here are some questions to motivate students to have more information before applying the case:

- How effective were the HC's actions to react to the health crisis triggered by the COVID-19 pandemic? What other actions could have been implemented?

- What are the main challenges to manage the care capacity for COVID-19 patients in a hospital environment? 


\section{DISCUSSION QUESTIONS}

The discussion focuses on the necessary adaptations of HCFMUSP operations from the outbreak of the COVID-19 pandemic in the state of São Paulo. To this end, we sought to prevent the care collapse and avoid the state health system's crisis. The case discussion is planned for a 120-minute session, which can be adapted by the class profile and the teacher's planning. The following table presents the critical questions for discussion and the expected duration for each section for the stages of Setting Construction, Action, and Health System Innovation.

Table 1. Key questions for discussion.

\begin{tabular}{|c|c|c|c|}
\hline Stage & Section & Key questions & Duration \\
\hline Introduction & 1. Introduction & In the short term, how could HCFMUSP react to this imminent health crisis? & $10^{\prime}$ \\
\hline \multirow{3}{*}{$\begin{array}{l}\text { Setting } \\
\text { construction }\end{array}$} & $\begin{array}{l}\text { 2. Brief history of } \\
\text { the emergence of } \\
\text { COVID-19 globally } \\
\text { and in Brazil }\end{array}$ & $\begin{array}{l}\text { How has the advancement of COVID- } 19 \text { globally and in Brazil influenced the decision-making } \\
\text { process regarding operations at HCFMUSP? } \\
\text { What are the main indications that allowed predicting the disease's behavior in Brazil? }\end{array}$ & $10^{\prime}$ \\
\hline & $\begin{array}{l}\text { 3. The health sector } \\
\text { context }\end{array}$ & $\begin{array}{l}\text { How did the main bottlenecks in the health value chain for adequate treatment of the } \\
\text { COVID- } 19 \text { crisis in Brazil influence HCFMUSP's operations? }\end{array}$ & $10^{\prime}$ \\
\hline & $\begin{array}{l}\text { 4. The HCFMUSP } \\
\text { Complex }\end{array}$ & $\begin{array}{l}\text { How does the HCFMUSP organizational structure influence the process of operational change } \\
\text { required in the face of the crisis? }\end{array}$ & $5^{\prime}$ \\
\hline \multirow{3}{*}{ Action } & $\begin{array}{l}\text { 5. Action against } \\
\text { the pandemic (crisis } \\
\text { management) }\end{array}$ & $\begin{array}{l}\text { What governance characteristics marked the decision-making process until operational } \\
\text { decision-making? } \\
\text { What are the changes brought about by the Crisis Committee in HCFMUSP operations? }\end{array}$ & $20^{\prime}$ \\
\hline & $\begin{array}{l}\text { 6. Service capacity } \\
\text { management }\end{array}$ & What are the main challenges to expanding capacity? & $20^{\prime}$ \\
\hline & $\begin{array}{l}\text { 7. Possible COVID-19 } \\
\text { treatments }\end{array}$ & How did the advancement of FMUSP studies and research impact operational strategies? & $10^{\prime}$ \\
\hline $\begin{array}{l}\text { Health system } \\
\text { innovation }\end{array}$ & $\begin{array}{l}\text { 8. Learning and the } \\
\text { post-COVID }\end{array}$ & $\begin{array}{l}\text { What opportunities for innovation in the management of health operations did the lessons } \\
\text { learned from combating COVID-19 provide to HCFMUSP? }\end{array}$ & $15^{\prime}$ \\
\hline Conclusion & 9. Next steps & How should the HCFMUSP operations area proceed with the advancing pandemic? & $20^{\prime}$ \\
\hline
\end{tabular}

Note. Source: authors.

\section{DISCUSSION AND LESSON PLAN}

\section{Introduction}

The instructor should encourage students to describe the nature of the actions proposed by $\mathrm{HC}$ in the face of the crisis ahead to answer the discussion question - "In the short term, how could HCFMUSP react to this imminent health crisis?" Some expected answers would be:

1. In 'governance,' through the resettlement of the Crisis Committee, which became the center of decisions and responsible for managing processes related to the Central Institute's work.

2. In the 'increased productive capacity', implying measures in human resources management, supplies, institutional relations, and contracts. There was a need to control donations and partnerships with private organizations.

3. In the 'innovation of treatments, procedures, and diagnoses,' given the need to develop specific COVID-19 protocols, integrating with the Faculty of Medicine's research mission.

\section{Emergence of COVID-19 globally and in Brazil}

The guiding questions draw the attention to the pressure factors for decision-making by the group gathered at Incor: the speed of the disease's progress globally and the indicators that allowed predicting its progress in Brazil.

At this point, we suggest simulating the meeting, starting with Dr. David Uip's report on the global trend of 
the disease and HCFMUSP's concern about how to address the issue internally.

The central pressure factors on the discussion are:

(1) How did the advancement of COVID-19 influence the decision-making process at HCFMUSP?

- Identification of a new type of coronavirus in China;

- The rapid spread of the coronavirus across Asia and Europe;

- Collapse in service in Italy and Spain;

- In Brazil, the identification of the first case of coronavirus immediately after Carnival, following confirmed agglomerations.

(2) What are the main indications that allowed predicting the behavior of the disease in Brazil?

- Initial forecasts of the need for 10,000 to 11,000 ICU beds in Greater São Paulo, as international studies pointed to $4 \%$ of cases requiring ICU;

- Identification that COVID-19 patients had a mean ICU stay of 15 days;

- High mean ICU occupation due to all diseases;

- Difficulties with diagnoses;

. No evidence of treatment and vaccine.

Next, the instructor should prepare students to expand their vision for the health sector context, with a brief explanation of the health value chain model (Figure 1), identifying its links and preparing students to discuss the following item.

\section{Health sector context}

The context analysis should lead the student to understand the scope of the value chain and relate the challenges in each link of this chain, influencing strategies to combat COVID-19 in the state of São Paulo — in particular, the operational actions established by the HCFMUSP. The proposed discussion question aims to identify: How can the main bottlenecks of the health system in addressing the COVID-19 crisis influence HCFMUSP's operations?

The student must refer to the health value chain (Figure 1) to answer this question, discussing the main bottlenecks and potential problems for each link:

Consumption: adherence of patients to treatments and of the population to preventive measures. Otherwise, the projected increase in demand would be affected, making collapse imminent.
- Financing: fluidity in obtaining resources from the Ministry of Economy and Ministry of Health, through action by the National Congress to ensure agility in supplying materials and equipment.

- Financial intermediation: clear compliance with the rules for access to the Health System (SUS). The Cross system should avoid attending patients at HCFMUSP who do not need to occupy its beds.

- Health services: qualification of professionals; obtaining a supply of PPE and respirators, highlighting the dependence on an external supply of these items, given the competition with the rest of the world.

- Distribution of health products and services: criteria for defining priority locations for a referral.

- Support and supplementary services: clinical engineering for equipment maintenance.

- Knowledge development: COVID-19 vaccines and treatments.

When identifying potential bottlenecks, students should check what additional actions to take to overcome them, showing operational management flexibility to accommodate difficulties and unforeseen events arising from the external context. The instructor should draw attention to the importance of HCFMUSP's governance and how it could support this flexibility.

\section{HCFMUSP's governance}

HCFMUSP is a traditional institution in the field of health, with missions in care and research. The central aspect to be addressed is: How can HCFMUSP's organizational structure influence the process of operational change required in the face of the crisis?

The hospital's organizational structure is matrix-based, which requires integration, given the specialized origin of each institute and the supervision of the services under the responsibility of the professors of the Faculty of Medicine. Its governance requires the councils' approval concerning the significant decisions, which demands organization and time to obtain collegiate decisions, hurdles in the face of the need to take emergency actions.

The student must think about the organizational structure of HCFMUSP and reflect on the governance system required to face the challenges. The instructor can call two students to stage a meeting to discuss the need to adapt operations. Meeting agenda: create a Crisis Committee or use the existing organizational structure. The study of the advantages and disadvantages of the alternatives is an input for discussing the next item. 


\section{Action against the pandemic}

The mobilization for HCFMUSP's reaction to the pandemic was influenced by the governance system and its ability to adapt. When urgency was knocking at the councils' door to approve emergency measures, the governor's visit and his immediate approval of the first capacity expansion proposal anticipated decision-making, which had been carried out traditionally.

The discussion questions address the main characteristics of governance that marked the decisionmaking process and the Crisis Committee changes in the organizational structure's functioning.

(1) What governance characteristics marked the decisionmaking process until operational decision-making? What are the changes brought about by the Crisis Committee in HCFMUSP operations?

Points to address:

- Corporate governance: Deliberative Council for the HCFMUSP and Directing Council for the Central Institute.

- Reinstatement of the Crisis Committee, with impacts on operations.

- The leading role of the Crisis Committee before the structure's executive bodies: command line for shortand medium-term operational decisions.

The instructor must draw attention to the nature of the necessary adaptations in human resources, supplies, distribution logistics, institutional partnerships, and servicing special situations. It is worth describing how these areas operate in daily situations to introduce the capacity management discussion.

\section{Service capacity management}

The guiding question for this item - "What are the main challenges to expanding capacity?" - must be answered by addressing the following topics:

Allocation of human resources: removal and relocation of professionals from risk groups; hiring and training new professionals; mobilization of full professors; relocation of residents.

- Supply of PPE, mechanical fans, and distribution logistics: discontinuity in the flow of materials; transfer between mechanical ventilator institutes, insufficient in the face of demand; articulation with other service areas.
- Demand adaptations: transforming wards into ICUs (second phase); care for pregnant women and psychiatric patients with COVID-19.

- Partnership management (donations and support from private organizations): contracts; donations screening; management of private partners' teams.

It is worth highlighting the importance of integration and complementarity between all action fronts. Institutes without COVID-19 patients, which housed patients from the Central Institute, played an important role in institutional cooperation.

After this discussion, the instructor should focus on the need for reorientations in studies and research to streamline support for the operation. It is recommended to address the mean length of stay and assess its suitability for the emergency established by the pandemic.

\section{Possible COVID-19 treatments}

This item's guiding question focuses on the need for integration between care and research areas to develop effective treatments, enhancing operational strategies.

(1) How did the advancement of FMUSP studies and research impact the operational strategies?

Points to address:

- HCFMUSP as a teaching hospital, emphasizing scientific grounds for treatments. These factors could hinder the speed of operations in the care of COVID-19 patients.

- Clinical research timing: protocols defining criteria for inclusion and exclusion of patients. Hospital structure and number of patients allow comparing the use of various drugs in patients from groups of similar clinical conditions. There is a need to reconcile scientific rigidity with agility for the effective treatment of patients.

A summary of the items discussed to introduce a reflection on the next steps would be recommended at this stage.

\section{Next steps}

Discuss the three possibilities of conduct in the face of the situation of the pandemic in May 2020:

a. Do we further increase the service capacity in the ICUs? How do we do this?

b. Do we maintain the installed capacity, given that it was expected that the regulation (external by the 
Cross system and internal by the Control On-call) would prevent the collapse in its attendance (without considering the collapse in the public health system of the state of São Paulo's attendance)?

c. Do we start the demobilization of the actions implemented to rebalance operations?

The guiding question of this item ("How should HCFMUSP proceed in the face of the advancing pandemic?") suggests reevaluating the external context and the progress in the treatments and protocols obtained until the discussion of the case.

In São Paulo, it is known that the disease progression stabilized in June 2020, decreasing consistently from September 2020. This enabled maintaining the installed capacity followed by a gradual demobilization of these beds (dedicated to the COVID-19). Additionally, advances in treatments and improvements in operational protocols contributed to a declining mean length of stay (15 to 12 days), which led to a lower bed occupancy rate. However, as of October 2020, the pandemic increased again, leading to new decisions.

\section{CONCLUSION}

The instructor can display a 4.5-minute video (Jornalismo TV Cultura, 2020) summarizing the mobilization made for the Central Institute's dedication to caring for COVID-19 patients, with statements from professionals participating in the process. In the end, integrated analysis is necessary, referring to the analytical-conceptual model presented in Figure 1, with the set of factors to consider when adapting HCFMUSP operations to serve patients requiring hospitalization. In the analysis proposal, the bold elements refer to intervening factors in the diagram shown in Figure 1.

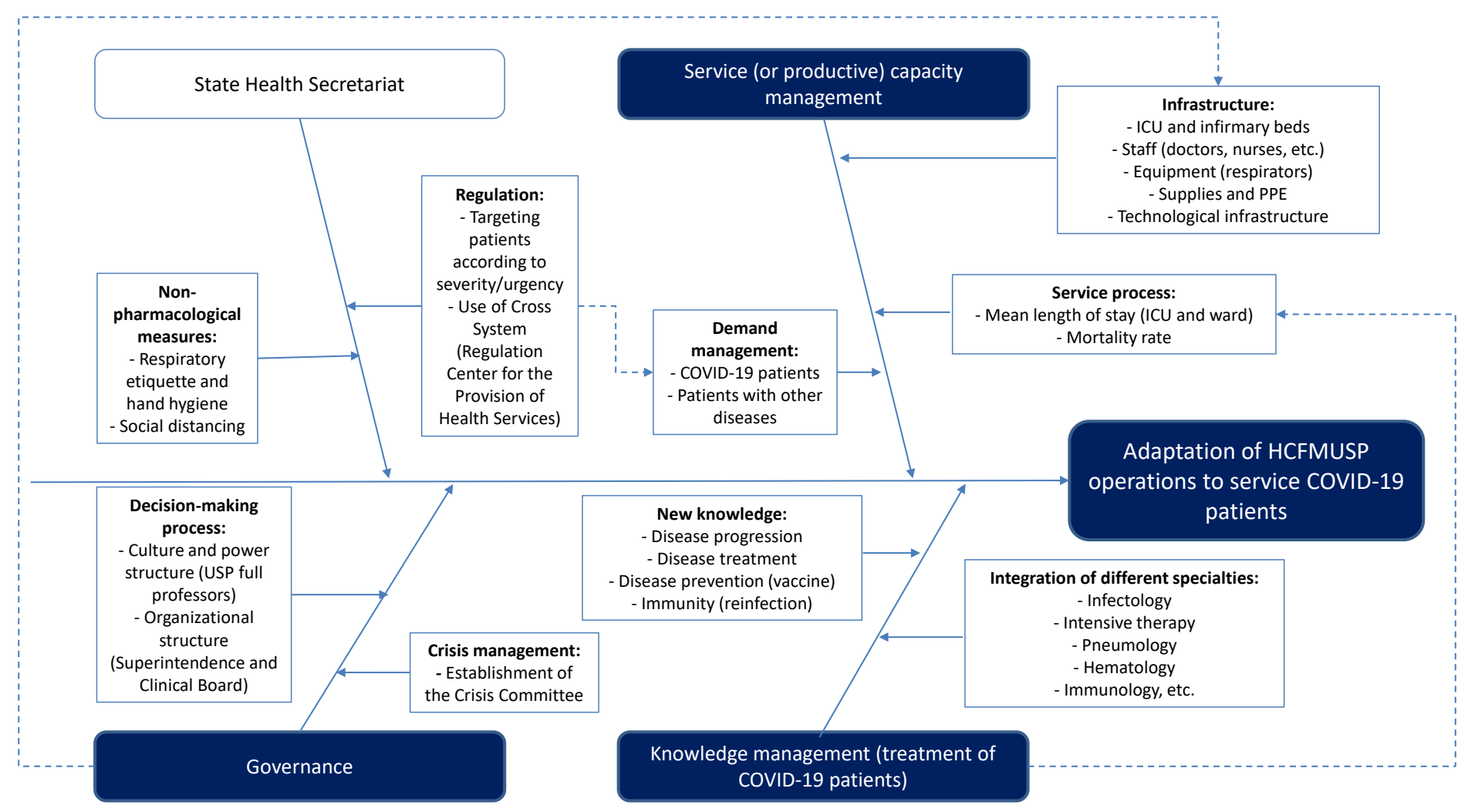

Figure 1. Analytical-conceptual chart.

Source: Authors. 
The main component of 'crisis management' was the installation of the committee created due to the recognition by $\mathrm{HC}$ of the imminent health crisis in Brazil and São Paulo. With a focus on productive capacity management, the challenge was to prepare the $\mathrm{HC}$ to address the sudden and high demand for COVID-19 cases without knowing the appropriate treatments (immediate issue).

Regarding 'demand management,' should HCFMUSP analyze the COVID-19 demand in the state of São Paulo? In reality, this analysis was carried out by the Contingency Center of the State of Sáo Paulo, which was established to monitor and coordinate actions against the spread of COVID-19. Students can check the situation of demand in the state (called the epidemiological situation) at the Sáo Paulo Health Secretariat (Secretaria da Saúde de São Paulo, 2020). With this information, the São Paulo Health Secretariat could make the decisions to increase state capacity, as in contracting COVID-19 beds from the HCFMUSP and other institutions (for example, the implantation of field hospitals).

Thus, it appears that demand management was outside the scope of HC's decision. The disease's progression could be mitigated by 'non-pharmacological measures,' such as respiratory etiquette, hand hygiene, and social distancing rules. 'Regulation,' that is, patient referral to the $\mathrm{HC}$, was controlled by the Cross system under the São Paulo State Health Secretariat's coordination office.

The HC was left out to act on its 'productive capacity' (service capacity). The main limiting factor was the ICU beds. Therefore, the main question was: How does one quickly increase the productive capacity (mainly ICU beds) to serve COVID-19 patients? (fundamental issue).

Regarding 'infrastructure,' the increase in ICU beds could be carried out in different institutes, creating a problem, namely, hospital infection control. The most plausible solution would be gathering COVID-19 patients in one location. The most viable solution would be to concentrate them in the largest institute (the Central Institute). In this case, the governor was a catalyst for the decision.

The care concentration of COVID-19 patients at the Central Institute (ICHC) created a 'governance' problem: the ICHC houses several specialties under the responsibility of full professors of the Faculty of Medicine. A collegiate decision would be required regarding the decision-making 'process,' and this could take time. However, it was rushed by the governor's attitude. The definition of making the ICHC an institute dedicated to COVID-19 shifted decisions from full professors (responsible for the different areas) to the Crisis Committee.

Once the governance issue was resolved, the problem became the 'productive capacity management.' The decision was taken to transform/adapt 200 ICHC ICU beds to COVID-19. There was a mobilization to adapt the infrastructure: (a) people: sizing/hiring intensive care teams; (b) equipment: adaptation/purchase of respirators; (c) supplies and materials (masks, gloves); (d) adequacy of the infrastructure. A second capacity adaptation was necessary, with a 100 -bed increase (total $=300$ ICU beds).

The ICU capacity management depends on beds' availability and the mean length of stay (since service capacity in the period $=$ beds ${ }^{*}$ mean length of stay in the period). The calculation for 200 beds and 15 days of hospitalization is shown below:

Service capacity (patient-months $)=200$ beds $*[(30$ days $) /(15$ days) $]=200 * 2=400$ patient-months.

Reducing hospital mean lenght of stay from 15 to 12 days, maintaining the number of beds, results in a $25 \%$ increase in service capacity:

Service capacity (patient-months $)=200$ beds $*$ [(30 days $) /(12$ days) $]=200 * 2.5=500$ patient-months.

The mean length of stay depends on 'new knowledge' about treatment. Critically ill patients were allocated to the HC. The less severe cases were referred to other services. Therefore, it was necessary to intervene in 'knowledge management' about the COVID-19 treatment to reduce lethality and length of hospital stay, which could be done through: (a) Integration of different medical specialties involved; and (b) New knowledge on progression, treatment, prevention, and immunity.

The ability to adapt the governance system, through the functioning of the Crisis Committee and the integrated and coordinated efforts by the member teachers of Condir and Condel, was decisive in achieving the results. The recruitment and training of new professionals and internal transfers were fast.

In June 2020, the disease's progression stabilized in São Paulo and has been consistently declining since September. This allowed maintaining the installed capacity followed by a gradual demobilization of these beds (dedicated to the COVID-19). Thus, until November 2020, it was evident that there would be no need for a further increase in the ICU care capacity for COVID-19 at HCFMUSP. However, the picture changed again in November. 


\section{REFERENCES}

Bayntun, C., Rockenschaub, G., \& Murray, V. (2012). Developing a health system approach to disaster management: A qualitative analysis of the core literature to complement the WHO Toolkit for assessing health-system capacity for crisis management. PLoS currents, 4, e5028b6037259a. http://dx.doi.org/10.1371/5028b6037259a

Bennington, L. (2010). Review of the corporate and healthcare governance literature. Journal of Management \& Organization, 16(2), 314-333. http://dx.doi.org/10.5172/jmo.16.2.314.

Bohmer, R. M. J. (2009). Designing care: Aligning the nature and management of health care. Boston: Harvard Business Press.

Jornalismo TV Cultura. (2020, April 2). Covid-19: Hospital das Clinícas cria espaço para 900 leitos para a doença \{Video file]. Video posted to https://youtu.be/TdBgm4FcSOo

Paim, J., Travassos, C., Almeida, C., Bahia, L., \& Macinko, J. (2011). The Brazilian health system: History, advances, and challenges. Lancet, 377(9779). http://dx.doi.org/10.1016/S0140-6736(11)60054-8
Pedroso, M. C., \& Malik, A. M. (2012). Cadeia de valor da saúde: Um modelo para o sistema de saúde brasileiro. Ciência \& Saúde Coletiva, 17(10), 2757-2772. http://dx.doi.org/10.1590/s1413-81232012001000024

Secretaria de Saúde de São Paulo. (2020). CVE - Centro de Vigilância Epidemiológica "Prof. Alexandre Vranjac". Retrieved from http://www.saude.sp.gov.br/cve-centrode-vigilancia-epidemiologica-prof.-alexandre-vranjac/ areas-de-vigilancia/doencas-de-transmissao-respiratoria/ coronavirus-covid-19/situacao-epidemiologica

Vecina Neto, G., \& Malik, A. M. (2016). Gestão em saúde (2. ed.) São Paulo: Editora GEN.

Zane, R., \& Prestipino, A. (2004). Implementing the Hospital Emergency Incident Command System: An integrated delivery system's experience. Prehospital and Disaster Medicine, 19(4), 311-317. http://dx.doi.org/10.1017/S1049023X00001941 


\section{Authorship}

\section{Marcelo Caldeira Pedroso*}

Universidade de São Paulo, Faculdade de Economia, Administração e Contabilidade

Av. Prof. Luciano Gualberto, no 908, Butantã, 05508-010, São Paulo, SP, Brazil.

E-mail address: mpedroso@usp.br

(1) https://orcid.org/0000-0002-2623-293X

\section{João Teixeira Pires}

Universidade de São Paulo, Faculdade de Economia, Administração e Contabilidade

Av. Prof. Luciano Gualberto, no 908, Butantá, 05508-010, São Paulo, SP, Brazil.

E-mail address: joaotp55@hotmail.com

(1) https://orcid.org/0000-0003-4821-6217

\section{Ana Maria Malik}

Fundaçáo Getulio Vargas, Escola de Administração de Empresas de São Paulo

Av. 9 de julho, mo 2029, Bela Vista, 01313-902, São Paulo, SP, Brazil.

E-mail address: ana.malik@fgv.br

(1) https://orcid.org/0000-0002-0813-8886

\section{Antonio José Rodrigues Pereira}

Fundaçáo Getulio Vargas, Escola de Administração de Empresas de Sáo Paulo

Av. 9 de julho, mo 2029, Bela Vista, 01313-902, São Paulo, SP, Brazil.

E-mail address: antonio.pereira@hc.fm.usp.br

(1) https://orcid.org/0000-0002-8287-323X

* Corresponding Author

\section{Funding}

The authors reported that there is no financial support for the research in this article.

\section{Conflict of Interests}

The authors have stated that there is no conflict of interest.

\section{Authors' Contributions}

$1^{\text {st }}$ author: conceptualization (lead); formal analysis (equal); project administration (lead); supervision (lead); validation (lead); writing-original draft (equal); writing-review \& editing (lead).

$2^{\text {nd }}$ author: conceptualization (equal); formal analysis (lead); writing-original draft (lead); writing-review \& editing (equal).

$3^{\text {rd }}$ author: conceptualization (equal); formal analysis (equal); validation (equal); writing-original draft (equal); writing-review \& editing (lead).

$4^{\text {th }}$ author: conceptualization (equal); data curation (lead); validation (equal); writing-review $\&$ editing (equal).

\section{Copyrights}

RAC owns the copyright to this content.

\section{Plagiarism Check}

The RAC maintains the practice of submitting all documents approved for publication to the plagiarism check, using specific tools, e.g.: iThenticate.

\section{Peer Review Method}

This content was evaluated using the double-blind peer review process. The disclosure of the reviewers' information on the first page, as well as the Peer Review Report, is made only after concluding the evaluation process, and with the voluntary consent of the respective reviewers and authors.

\section{Data Availability}

RAC encourages data sharing but, in compliance with ethical principles, it does not demand the disclosure of any means of identifying research subjects, preserving the privacy of research subjects. The practice of open data is to enable the reproducibility of results, and to ensure the unrestricted transparency of the results of the published research, without requiring the identity of research subjects. 